\title{
Learn from your environment: A visual literacy learning model
}

\author{
Matthew Guinibert
}

Auckland University of Technology

\begin{abstract}
Based on the presupposition that visual literacy skills are not usually learned unaided by osmosis, but require targeted learning support, this article explores how everyday encounters with visuals can be leveraged as contingent learning opportunities. The author proposes that a learner's environment can become a visual learning space if appropriate learning support is provided. This learning support may be delivered via the anytime and anywhere capabilities of mobile learning (m-learning), which facilitates peer learning in informal settings. The study propositioned a rhizomatic m-learning model of visual skills that describes how the visuals one encounters in their physical everyday environment can be leveraged as visual literacy learning opportunities. The model was arrived at by following an approach based on heuristic inquiry and user-centred design, including testing prototypes with representative learners. The model describes one means visual literacy could be achieved by novice learners from contingent learning encounters in informal learning environments, through collaboration and by providing context-aware learning support. Such a model shifts the onus of visual literacy learning away from academic programmes and, in this way, opens an alternative pathway for the learning of visual skills.
\end{abstract}

Implications for practice or policy:

- This research proposes a means for learners to leverage visuals they encounter in their physical everyday environment as visual literacy learning opportunities.

- M-learning software developers may find the pedagogical model useful in informing their own software.

- Educators teaching visual skills may find application of the learning model's pedagogical assumptions in isolation in their own formal learning settings.

Keywords: m-learning, rhizomatic learning, visual literacy, visual communication, practicebased research

\section{Introduction}

Today visuals are an important medium for communication, placing pressure on the average person to understand and use visuals to fully participate in the contemporary world (Hanifan, 2008; Marcum, 2002,). Accordingly, scholars have highlighted a need for visual literacy and its learning (Arnheim, 1969; Spalter \& Van Dam, 2008). New Zealand's Tertiary Education Commission also calls attention to the need for visual skills by including them, among other traditional literacy competencies, as part of how they define adult literacy (Tertiary Education Commission, 2008). Despite repeated calls for visual literacy, Arnheim (1969), Dondis (1973), and Bleed (2005) have argued that formal education has been slow to respond. Rather than attempt to address the blockages in formal education, this study explored how visual literacy skills may be acquired in informal learning settings. Specifically, the aim of this research was to create a pedagogical model that describes how the visuals one encounters in their physical everyday environment can be leveraged as visual literacy learning opportunities. This exploration utilised heuristic inquiry and user-centred design to create a pedagogical model consisting of nine key pedagogical assumptions.

The impetus for this research was a personal problem. The researcher, an educational technologist and a lecturer of visual communication, user interface, and user experience design, wanted to explore learning support for his own students. However, the outcome has further implications. For visual literacy learners, the approach to learning derived from this research may allow them to use contingent learning encounters with visuals from their environments as learning opportunities. This contingent style of visual learning may allow for visual literacy acquisition to occur as a by-product of a learner's daily interaction with their environment, converting a learner's environment into a visual learning environment. The learning model may be of use to educators of visual communication and to software developers as a framework for visual literacy learning. The learning model's pedagogical assumptions in isolation may also be of use to educators for use in formal learning settings. 


\section{Visual analysis as a learning means}

Stokes (2002) stated that there are two major approaches for learning visual literacy skills. The first, on which this study focuses, involves learners practising analysis techniques so that they may learn to decode, or read, visual stimuli. The second involves learners practising to encode, or write, visuals for communicative purposes and is outside the scope of this study. Why one should practise analysis can be traced back almost 100 years to Helmholtz (1925), who claimed that what we perceive is the result of raw sensory information, visual memories, and mental processes. Therefore, the more visual memories a person has, the more clearly they will perceive. Lester (2017) continued this line of thought, arguing that analysis of visuals creates a memorable experience and allows one to internalise lessons from a visual. Therefore, visual analysis can be considered both a core skill and a method for learning.

\section{A problem with learning visual literacy}

This research operated on two presuppositions: (1) examples of visual communication are a ubiquitous resource in one's environment, and (2) visual analysis is a means of learning visual literacy skills. These two presuppositions combined raise a line of enquiry; if the visuals we encounter everyday can be leveraged as visual literacy opportunities by practicing visual analysis, then learners' everyday environments could potentially become learning environments that immerse them in visual learning as they go about their day. However, if all a learner had to do was think critically about the images they encounter, obtaining visually literacy skills would be a simple undertaking and learners could potentially learn by osmosis. This does not appear to be the case and some learning intervention is needed.

An examination of the literature on learning to analyse and decode imagery as a means of acquiring visual literacy skills reveals visual learning is a circular reference, which is potentially problematic. Perception and visual analysis require, and are influenced by, memories and experiences, but memories and experiences are created through perception and visual analysis (Helmholtz, 1925; Jamieson, 2007). Rock (1997) referred to this as a perception-perception chain of causation, where one perception enables another. Lester (2017) describes this as a closed loop of sense, select, perceive, remember, learn, and know. When visual literacy learning is theorised as a circular reference, then the novice learner encounters a dilemma. To sense and select, one must first know, but to know, one must first sense and select (Figure 1). Where does a novice begin?

The circular reference can be overcome by providing learning support. This support can be provided by transferring or prompting the construction of knowledge, or by highlighting what to select to begin the visual learning process (Figure 1). In formal learning scenarios, this support can come from an expert or peers. However, outside of formalised learning (i.e., informal learning scenarios), this is more complicated as there may be no expert or peers to provide support. This may explain the earlier point, that visual literacy is not acquired by osmosis, as although learners have visuals to analyse in their environments, they lack support. 


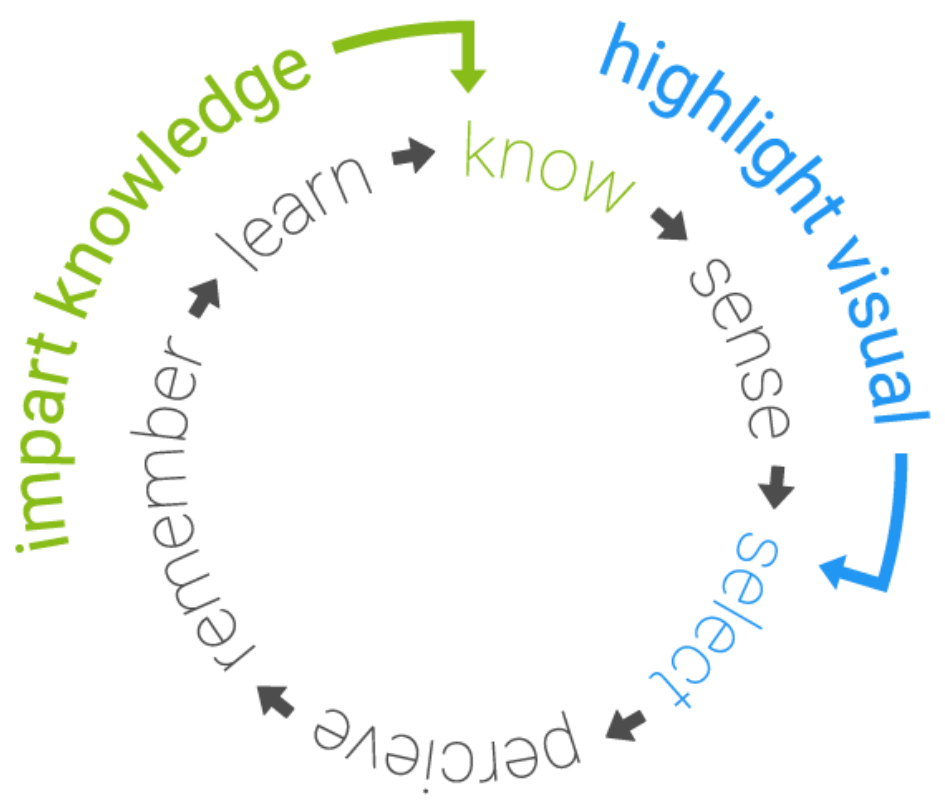

Figure 1. Author's adaptation of Lester's (2017) diagram of visual learning to show entry points into the circular reference system.

The idea of support is validated by a branch of cognitive constructivist theory, social constructivism, in particular Vygotsky's (1978) theory of the zone of proximal development. Essentially, the zone of proximal development describes the difference between what a learner can achieve on their own, compared to if they had guidance or operated in collaboration with more experienced peers (Figure 2). Vygotsky (1978) proposed that support should be provided so that learning can occur in an individual's zone of proximal development, creating scaffolds to encourage further learning. Relating this back to visual literacy and its learning, it can be argued that learning from encounters with visuals is beyond a novice learner's abilities. Therefore, if there could be some way to support learners in their daily environment, learning could potentially occur.

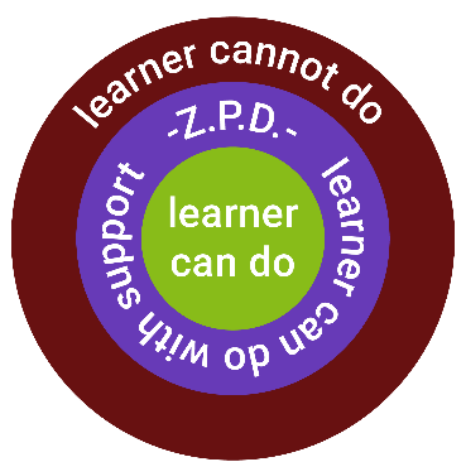

Figure 2. Author's illustration of Vygotsky's (1978) zone of proximal development (ZPD).

\section{M-learning, a potential solution}

There is little information on how support can be provided to overcome the visual learning circular reference dilemma outside of formal learning scenarios. However, research does exist on supporting learners (not specifically those of visual literacy) in the form of mobile learning (m-learning) when 
physically or temporally separated from traditional or formal learning. M-learning's ability to journey with learners across time and space allows it to be used everywhere and every time (Georgiev, Georgieva, \& Smrikarov, 2004). This leads to learning that can be more situated in a learner's surroundings (Gikas \& Grant, 2013), which is an attractive proposition when considering how learners can learn from life's everyday imagery when they are separated from traditional learning support. Further m-learning that can provide new learning opportunities as highlighted by Traxler (2011), namely, contingent learning, situated learning, authentic learning, context-aware learning, and personalised learning. Applying these affordances of m-learning to learning visual literacy skills may provide learners more opportunities to learn as they would have persistent access to some form of support, which has the potential to turn everyday life into a visual literacy learning opportunity.

\section{Rhizomatic learning}

As noted earlier, informal learning scenarios have no formally appointed teacher. Consequently, who would impart the knowledge or highlight visuals as shown in Figure 1 to begin the learning process in an informal m-learning scenario? Or, from another perspective, who would provide the scaffolding or peer support required by Vygotsky's (1978) zone of proximal development? One potential answer could be other learners in a rhizomatic learning community.

In the rhizomatic learning model, the curriculum is not predefined by experts or teachers, instead, "community acts as the curriculum, spontaneously shaping, constructing, and reconstructing itself and the subject of its learning in the same way that the rhizome responds to changing environmental conditions" (Cormier, 2008, p. 5). The learning model is an adaption of rhizomatic thinking, originally proposed by Deleuze and Guattari (1987), in order to overcome educational limitations in subjects that are new, evolving, and do not have an accepted canon of knowledge (Cormier, 2008). Visual literacy and visual communication both suffer from a lack of widely accepted definitions (Avgerinou \& Ericson, 1997) and a lack of universally recognised or canonical texts (Griffin, 2008). Consequently, previous studies have suffered by scoping visual literacy competencies too broadly to be of use to educators (Brill, Kim, \& Branch, 2007), or too narrowly to be of use beyond learning isolated aspects or specific practises (McMaster, 2015). Therefore, visual literacy learning may benefit from a rhizomatic approach.

\section{Methodology}

The aim of this research was to explore the question: How can everyday encounters with visuals be leveraged as visual literacy learning opportunities by providing learning support? The outcome of this exploration is a pedagogical model and a prototype for an m-learning application. This paper focuses solely on the pedagogical model. The model was arrived at by following a 3-stage research design (Figure 3) that utilised heuristic inquiry and user-centred design. The first two stages were a creative and an inductive process, while the third was deductive, seeking to validate and/or refine ideas.

Heuristic inquiry and user-centred design, while common in design domains, are not usually employed in educational research. Heuristic inquiry was selected for this specific study as it allowed for the researcher's own experiences to be utilised as a starting point for ideation. Heuristic inquiry allowed this research to be purposefully open-ended, using the research question as a compass rather than a destination. The phases of heuristic inquiry provide methods as sequential steps for conducting research. According to Moustakas (1990), these phases are: initial engagement, immersion, incubation, illumination, and explication.

Heuristic inquiry's strength is in its creative and flexible approach, but comes at the cost of clear methods. Therefore, heuristic inquiry's creative synthesis and validity phases were supplemented with methods from user centred design, which is a software design centric set of best-practices that provide a clear and rigorous process. User-centred design is defined as "the active involvement of users for a clear understanding of user and task requirements, iterative design and evaluation, and a multi-disciplinary approach" (Vredenburg, Mao, Smith, \& Carey, 2002, p. 472). User-centred design's focus on users (i.e., learners) and tasks rather than features allowed this research to focus on underlying pedagogy rather than technology, which is a common criticism of m-learning research (Selwyn, 2011). 


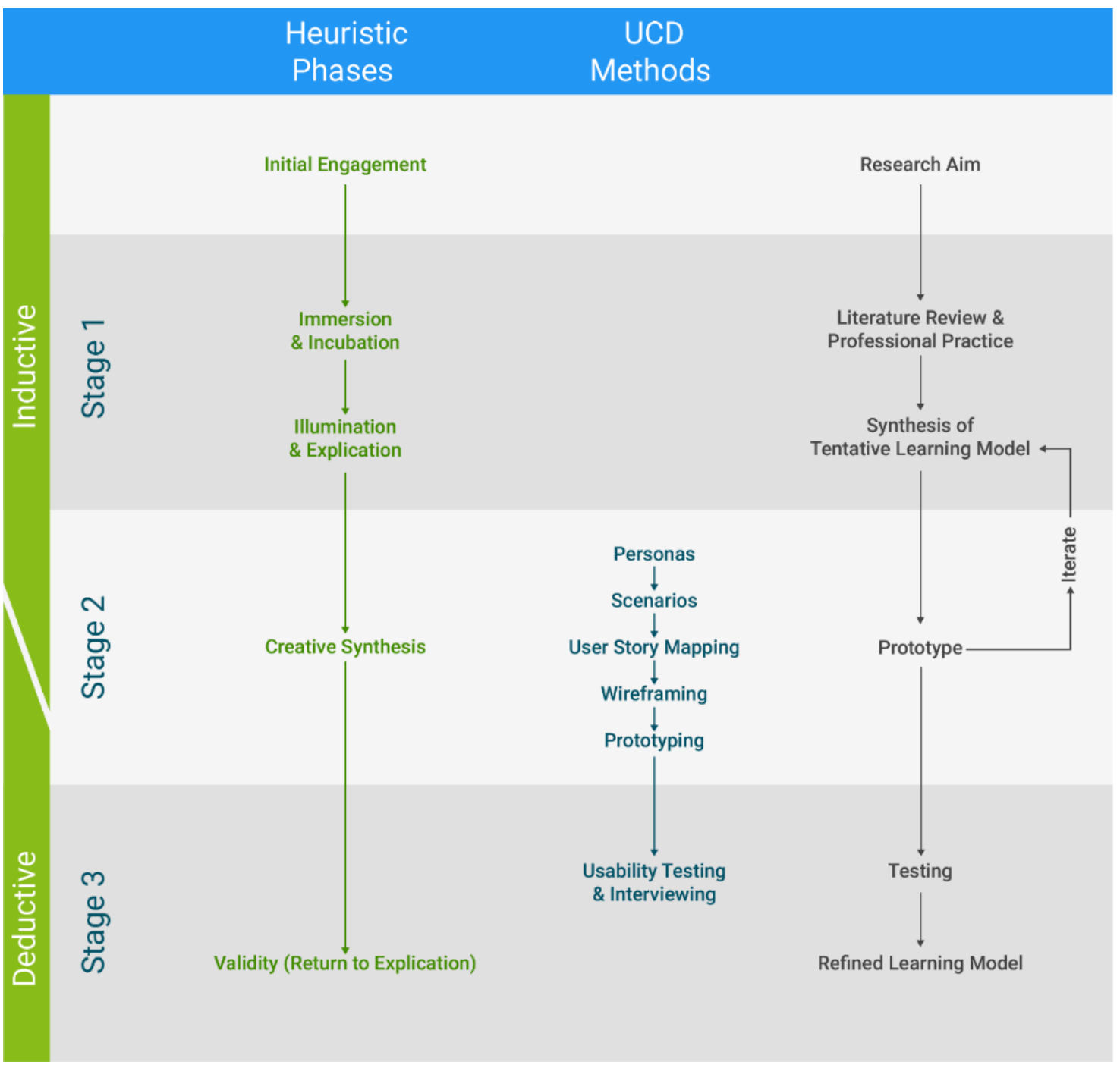

Figure 3: Diagram of this study's research design.

\section{Stage 1: Tentative pedagogical assumptions}

Ideas are not formed in a vacuum, but rather based on some form of literature review (Vogt, 2014). Therefore, a literature review was conducted to identify a tentative set of pedagogical assumptions that may describe how everyday encounters with visuals can be leveraged as visual literacy learning opportunities. The identified tentative set of pedagogical assumptions came from visual analysis as a learning means, Lester's (2017) model of learning visual literacy skills, Vygotsky's zone of proximal development, mlearning, and rhizomatic learning.

\section{Stage 2: Prototype}

Stage 2 sought to implement the tentative pedagogical assumptions by undertaking the design (preproduction) of an m-learning application. This allowed the pedagogical assumptions to be refined through practise using Schön's (1983) concepts of reflection-in-action and reflection-on-action. The methods utilised followed best practise in user-centred design, working through a process of creating user personas, scenarios, user story maps, wireframes, interactive low-fidelity prototypes, and interactive high-fidelity prototypes. The prototype also served to later test and further refine the tentative learning model in Stage 3. Thus, the prototype needs to be understood as an ideation means and test platform for the learning model, not a finished or commercialised product. 


\section{Stage 3: Test and refine}

Stage 3 tested the tentative set of pedagogical assumptions through usability-testing and interviewing to verify and refine them into a learning model. The usability testing and interviews were carried out as hour long sessions consisting of three components: introductory questions, test scenarios, and an interview. The introductory questions were open-ended questions that may inform the viability of the learning described by the tentative pedagogical assumptions. These questions were asked before participants were introduced to the prototype application or tenants of the pedagogical assumptions to gauge a need or desire for visual literacy learning in informal settings.

The test scenarios involved participants using the prototype application to attempt tasks. Test scenarios are stories that provide context and motivation for tasks that participant's attempt (Tan, Liu, \& Bishu, 2009). As participants completed scenarios they were asked open ended questions about the task they had completed, a practice that is referred to as retrospective think aloud (Olmsted-Hawala \& Bergstrom, 2012). Through retrospective think aloud, data on the participant's thoughts and the viability of the tentative learning model's pedagogical assumptions could be collected without distracting them from completing tasks.

Lastly, an interview was conducted consisting open-ended questions. Open-ended questions allowed flexibility to improvise follow-up questions based on the participant's responses (Kallio, Pietilä, Johnson, \& Kangasniemi, 2016). This reciprocity allowed the researcher to ask participants to clarify or further expand on ideas as they are presented. The questions were designed to elicit responses relevant to the tentative learning model's pedagogical assumptions and collect data on participants' experiences and perceptions on visual learning.

User-centred design recommends participants should be representative of those who will actually use the software under scrutiny (Martin \& Hanington, 2012). Therefore, students who were enrolled in an introductory visual communication course at Auckland University of Technology, New Zealand, were invited to participate in the study. Of the respondents to the invitation, five participants were selected based on the Nielsen-Landauer formula for usability-testing (Nielsen, 2012; Nielsen \& Landauer, 1993). Data was collected throughout the session by both recording the participant's person and the prototype's screen simultaneously.

The analysis procedures were taken from both heuristic inquiry (Moustakas, 1990) and usability testing (U.S. Department of Health and Human Services, 2006). This involved first organising the data, then transcribing the recordings to create a text searchable video database. The tentative set of pedagogical assumptions were then used to group responses and additional groupings were created for anything that fell outside their scope. Usability issues consisting of any mistakes, hesitations, and pathway deviations were also analysed to form a usability report of the prototype. The groupings and usability report were then used to identify themes, and textual descriptions were written for each. The themes and textual descriptions were then compared to the raw data to check that they are representative of the participants' thoughts and experiences and corrected as needed. Finally, the themes and their descriptions were settled upon and visualised to form a pedagogical model (presented in the next section).

\section{Learning model}

The overarching pedagogical assumption of the learning model is that persistent access to support and collaboration with more capable peers is required for novice learners to learn visual literacy decoding skills from visuals encountered in their everyday environment. This is supported by nine pedagogical assumptions and their sub-points. The learning model has been visualised to help demonstrate how the pedagogical assumptions may work together (Figure 4). The visualisation draws from the existing visualised models presented in Figures 1 and 2. The purple outer ring of Figure 4 represents the community and collaborative aspects of the learning model. This study found that community and collaboration can provide the learning material and learning support required for novices to learn from their environment. Given the importance of community and collaboration in making the learning style proposed by the learning model effective, they are depicted as encompassing all the pedagogical assumptions. 


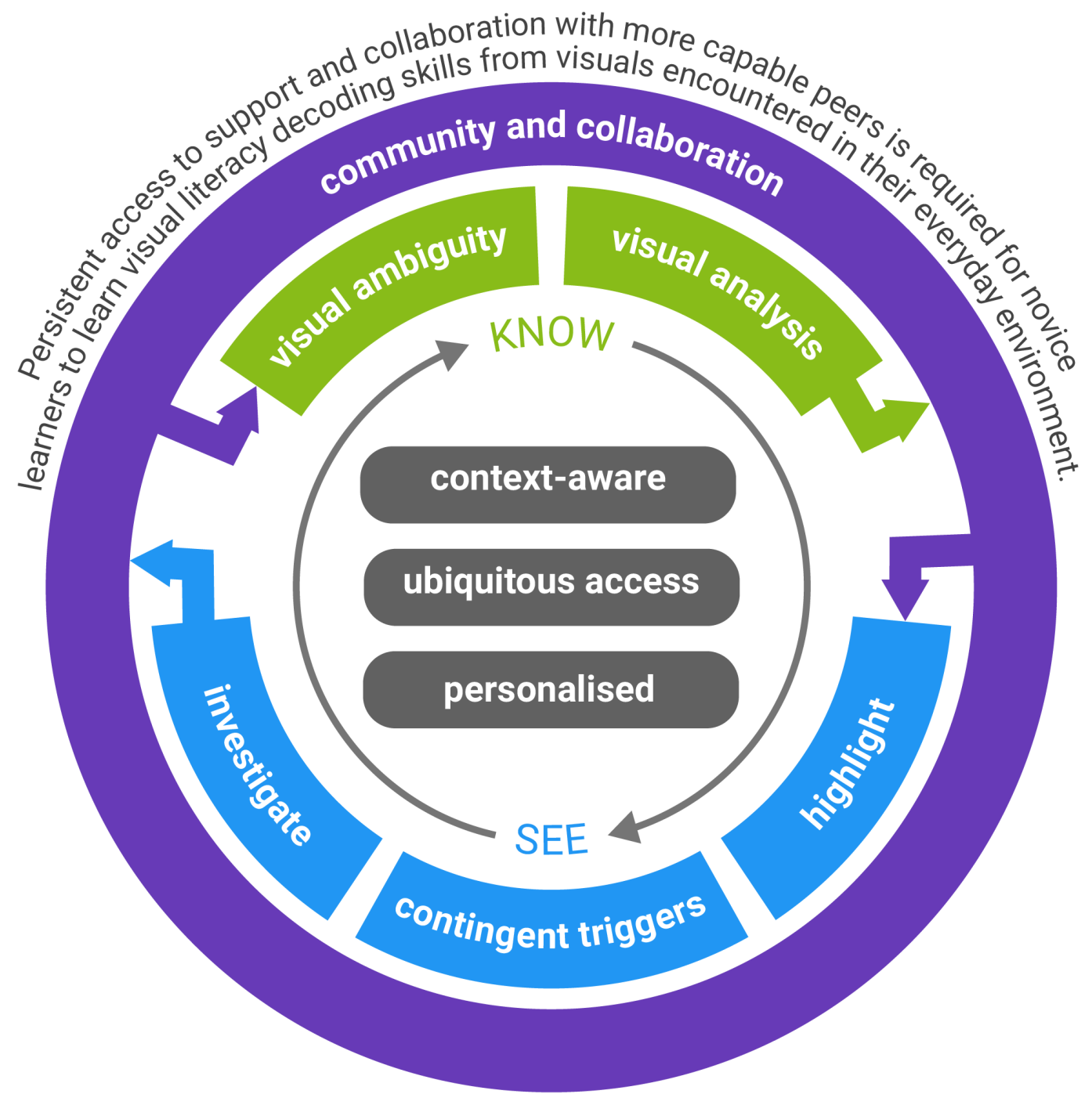

Community and collaboration: learning visual literacy is a collaborative activity.

- Provide a community that uses gamification mechanics to encourage collaborative learning.

- Make learners aware of social factors,

relating to their own activities, friends, interests, and location.

- The learning community should be decentralised.

Visual analysis: Conducting visual analysis of noteworthy examples of visual communication within a learner's environment provides a means for learners to more deeply engage with visuals and learn from them.

Visual ambiguity: Learners must impart and be receptive to different understandings of visual literacy.
Highlight: Provide a means to highlight or direct learners to examples of visual communication.

Contingent triggers: Learning is triggered by contingent encounters with examples of visual communication in a learner's environment.

Investigate: Learners need to examine and investigate their environment's examples of visual communication as a means of learning.

Context-aware: Provide context-aware learning.

Ubiquitous access: Provide ubiquitous access to learning support.

Personalised: Learning needs the ability to be personalised to accommodate a learner's environment, goals, interests, and preferences.

- Personalised learning also needs to include the means to limit learning.

Figure 4. Visualisation of the learning model proposed by this research. 
The next ring, containing green "know" and blue "see" elements, describes the pedagogical assumptions that relate to an individual learner's circular reference system of visual literacy learning. The green elements associate to the "know" domain of the circular reference system. The blue elements associate to the select and perceive domains of Lester's (2011) model (Figure 1) and are summarised as "see". The two aspects "know" and "see", are of importance as they represent two common entry points into visual literacy learning (Figure 1). They begin the process of internalising lessons from the community. Unlike Figure 1 however, which focuses on an individual receiving support, the learning model also considers an individual providing support back to other learners in community by either contributing visuals or adding to a visual's analysis. The arrows show this flow of providing and receiving support as both knowledge and seen visuals move between an individual learner and the learning community.

Lastly, the grey innermost boxes contain the pedagogical assumptions relating to an individual learner and their unique circumstances and environment. As visuals can be considered a ubiquitous resource in a learner's environment, ubiquitous access to learning support needs to be provided so that learners can leverage contingent encounters with visuals as learning opportunities. Context-aware learning also needs to be provided so that it can account for a learner's unique environment. This allows learning to dynamically change to reflect the circumstances or conditions that surround a learner so that contingent encounters may be leveraged. Personalised learning takes account of a learner's goals, interests, and preferences so learning may conform to each individual learner's circumstances and environment. Personalised learning also plays a role in limiting learning, so that a learner is not overwhelmed by the near limitless visuals in their environment that may be proposed for learning.

\section{Discussion of the learning model}

\section{Visual analysis and learning}

Pedagogical assumption 1: Conducting visual analysis of noteworthy examples of visual communication within a learner's environment provides a means for learners to more deeply engage with visuals and learn from them.

Barnes (2011), Gombrich (1982), Lester (2017), Stokes (2002), and Velders, Vries, and Vaicaityte (2007) all noted the importance of visual analysis in learning. Participants in this study corroborated this view by stating that they believed they learned when analysing visuals. There was a disconnect however, between the participants' experiences and their reflections on these experiences regarding their learning from contingent encounters. Participants were asked to recount a contingent encounter with a visual, which they all did, providing details and their analysis of the visual. This demonstrated that the participants' experiences of contemplating an encountered visual helped them to internalise it. However, when the participants were asked if they believed they had learned from the encounter, only two participants believed they had, while the other three described the experience as one of appreciation or practise. As practise is a means to refine and expand on learning through application, this therefore raises the question of what the participants perceived as learning. One participant's responses mirrors this disconnect as they spoke of using Pinterest (a social network for viewing and curating images) specifically for helping with their studies, but stated that they did not consider this learning as it does not impart procedures on how to achieve some specific technique. This participant appeared to perceive learning as only techniques they could operationalise. This may be a consequence of being a novice learner engaged with formal learning, and not perceiving anything outside their current learning objectives as learning. If this were the case, then the difference in participants' perceived learning from contingent encounters may have been due to varied levels of expertise. Another potential reason for this disconnect may lay in notions of tacit knowledge. Rourke and Rees (2015) claimed that tacit knowledge is often gained through experiences (such as contingent encounters), which lead individuals to develop intuitive visual skills that are subconscious and implicit. If this were the case, then some of the participants in this study may not have been conscious of their learning.

An interesting and unexpected result was that the participants repeatedly commented on a desire to analyse or engage with visuals that they described as either "good" or "bad" examples of visual communication, with a preference for bad examples. A possible explanation for these results can be found in socialcomparison theory, which posits that individuals will seek self-enhancement or improvements to their selfesteem by comparing themselves to others (Festinger, 1954; Wills, 1981). A person can compare through either an upward or a downward comparison. In a downward comparison, a person will look to another 
who they consider worse off as a means to feel better about themselves or their situation (Wills, 1981). A person will make an upward comparison with someone they perceive as better in some way as a means of self-enhancement, comparing similarities in themselves to the perceived positives of others (Suls, Martin, \& Wheeler, 2002). Participants' responses indicated that they compared themselves through their abilities as visual practitioners to those of others in the visuals they were noticing. Upwards and downwards comparisons may explain why the participants liked to analyse work that is notable for being either good or bad. Additionally, upward comparisons can sometimes have the opposite effect, decreasing a person's esteem as they may see themselves (or their skills as visual practitioners in this case) as inferior in the comparison (Suls et al., 2002). This may explain why some participants preferred to analyse poor examples, as doing otherwise may have negatively affected their self-worth.

\section{Inclusivity of visual literacy understandings}

\section{Pedagogical assumption 2: Learners must impart and be receptive to different understandings of visual literacy.}

Different understandings of visual literacy have led to issues of entrenchment that have encumbered research in visual literacy and its learning (Avgerinou \& Ericson, 1997; Griffin, 2008; McMaster, 2015). Accordingly, this pedagogical assumption is included (along with rhizomatic learning) so that the application of this learning model does not encounter similar issues. Participants of this study understood and were receptive to different understandings of interpreting visuals, however, only if they were supported in some way. Essentially, these participants were not concerned with the correct understanding, but rather the quality of explication. Given the informal and rhizomatic approach that underpins the learning model, what constitutes quality would be a decision made by the community through discussion and selfmoderation. In a best-case scenario, learners would debate ideas constructively, with peers asking for further explanation resulting in an analysis supported or rejected by the community. This process would see learning occur as a form of Vygotsky's (1978) social constructivism. In the worst-case scenario, differences in opinion among the learners within the community may result in online arguments rather than discussion, which was a concern raised by one participant.

A potential problem with the learning model was that some participants stated they would be hesitant in offering views in disagreement with others. This could lead to incorrect interpretations gaining traction. Cheong, Bruno, and Cheong (2012) reported a similar problem within online learning communities called groupthink, where learning communities tend to agree rather than offer a diversity of ideas. Groupthink is also a known issue with other existing online communities using up-vote systems, where the first up-votes or down-votes will likely set a trend for following votes (Muchnik, Aral, \& Taylor, 2013). The issue of groupthink also extends to visual perception, as a person can be easily made to ignore their own correct perceptions in favour of group consensus (Asch, 1955).

\section{Collaborative learning}

Pedagogical assumption 3: Learning visual literacy is a collaborative activity.

The rhizomatic component means that learning communities using the style of learning proposed by this model not only exists for learners to interact and access learning content, but also to produce it. Therefore, the collaborative component provides both the mechanism and material for learning to occur. Participants positively perceived learning visual literacy skills in collaborative settings. Further, participants described online collaborative learning for visual literacy as fun, interactive, entertaining, and engaging. This result is similar to those of Gikas and Grant (2013), who have reported about positive learner perceptions of social media used in learning, and Cheong et al. (2012), who noted millennials perceive online social interactions as enjoyable in learning.

Three supplementary assumptions to describe and set rules for the learning community were included in the third pedagogical assumption. The first supplementary assumption, to provide a community that uses gamification mechanics to encourage collaborative learning, affords a space for collaborative learning to occur. Cheong et al. (2012) reported that there is a potential for lack of focus, poor communication, dominant personalities, social loafing, and groupthink within learning communities. The prototype included, up-voting to accumulate points, badges, social engagement loops, and customisation options and were all received positively by the participants. These are common gamification features, often utilised in applications and social media platforms. Gamification is the idea that mechanics used in games can be used 
in non-game contexts as a means of increasing user engagement and motivation (Domínguez et al., 2013). The mechanics used in gamification have already been studied in e-learning applications by Muntean (2011) who reported that accumulating points, such as the up-votes in the participant's revelation, may be used as a means of rewarding behaviours and encouraging tasks within a learning community.

The second supplementary point, to make learners aware of social factors, relating to their own activities, friends, interests, and location, is about providing a shared context for learners to socialise, learn, and construct knowledge. Cheong et al. (2012) asserted that to achieve coordinated collaboration learners must be made aware of social factors which consist of who is around, what is going on, and how things are going. Participants were asked what social factors they would want to be made aware of. Participants spoke most about the ability to learn along with friends, perceiving this as motivational and fun. Participants also wanted to be informed of anything to do with themselves, such as replies to their own comments or posts. A desire for locational social factors was also mentioned by participants. These results are not surprising, as Gikas and Grant (2013) reported similar findings in their studies. It seems that millennials enjoy social media, and positively associate these aspects of social media with m-learning.

The third supplementary point, that the learning community should be decentralised, is included so that a learning community may have autonomy to organise itself. This provides a means for the community to socially construct knowledge rather than have it set by an individual or curriculum designer. The testing sessions collected participants' views and actions relating to the prototype's mechanisms for providing a decentralised system, including common features present on social media platforms including a tagging, an up-vote system, posting, and commenting. These features were perceived positively as a means for the community to come to consensus about what is desirable content.

\section{Contingent learning encounters}

Pedagogical assumption 4: Learning is triggered by contingent encounters with examples of visual communication in a learner's environment.

The proposed learning model operates on the premise that examples of visual communication are ubiquitous in a learner's environment and can be leveraged to acquire visual literacy skills. For this to occur, learning must be situated in a learner's environment, taking advantage of contingent learning opportunities. Participants responded to the idea of learning from contingent encounters with visuals in their environments positively, believing they all could learn this way, with some of the participants already doing so.

\section{Examining one's environment}

Pedagogical assumption 5: Learners need to examine and investigate their environment's examples of visual communication as a means of learning

The fifth pedagogical assumption encourages learners to seek out contingent encounters with examples of visual communication under their own direction. This pedagogical assumption was confirmed as purposeful, as some participants claimed to currently practise visual literacy by exploring their environments, applying existing knowledge to uncover connections, new knowledge, and deeper meanings of visuals. This situates this type of learning as a specific branch of constructivist learning called discovery or exploratory learning, which is based on the premise that our experiences shape or refine our knowledge and allow us to understand the world (Bruner, 1986). Exploratory learning encourages learners to examine and investigate new material or experiences, to discover relationships between existing knowledge and unfamiliar content, and concepts leading to learning (Bruner, 1961). Participants believed they needed some prior knowledge to be able to explore as a means of learning, and that they needed to be engaged with formal education to acquire this prior knowledge. Therefore, any implementation of this learning model may need to be supplemented with some type of formal education. This need to supplement with formal learning appears to be indicative of a wider problem with m-learning, which, according to Crescente \& Lee (2011), lacks evidence that it may stand in isolation, and is why m-learning is frequently implemented with other pedagogical strategies.

Another pattern in the participants' responses was that they believed exploring their environment for examples of visual communication was a valuable habit or a best practise. In a study by Park and Choi (2009), they found that a learner's perception of usefulness had a positive impact on their motivation to continue learning in a digital setting. Consequently, the participant's perception of value could be regarded 
as an intrinsic motivator. The perceived value and consequent intrinsic motivation provide impetus to engage with learning that offers no accreditation or appointed pedagogue to provide motivation, which makes a strong case for the learning model's application in informal settings.

\section{Highlighting}

Pedagogical assumption 6: Provide a means to highlight or direct learners to examples of visual communication.

The sixth pedagogical assumption, highlighting, is one means to trigger the fourth pedagogical assumption, learning through encounters with visuals. Participants responded positively to the idea of highlighting, perceiving it as both beneficial to their learning, and as an aid in developing habits they believed would be valuable as a visual practitioner. Highlighting represents the second entry point into the visual learning circular reference system (Figure 1). Whereas the fifth pedagogical assumption requires prior knowledge to select a visual for learning to occur, this sixth pedagogical assumption provides support for learners who lack prior knowledge, confidence, or the ability to select visuals to analyse. The need for highlighting was confirmed by one participant, who felt they would struggle to learn from their own explorations. This participant gave an account of previous learning in which an advertisement was pointed out to them, which they subsequently analysed and learned from. In this account, the participant's analysis and consequent learning were the result of the image being highlighted for them.

While using the prototype, a common theme was noted that participants believed highlighting would be fun. Although highlighting was intended to engage learners when inattentive or unaware of visuals in their environment, participants also perceived highlighting as an enjoyable mechanism to actively engage with. Participants envisioned themselves using highlighting like a radar or map to actively seek out visuals, then changing their location to experience those highlighted visuals. Participants drew comparisons to playing mobile games that use similar mechanisms. In particular, three participants mentioned the mobile game Pokémon Go, which was released a month prior to their participation in the research. The comparisons drawn between highlighting and the game show that highlighting has the potential to be a fun and engaging mechanism.

\section{Ubiquitous learning support}

Pedagogical assumption 7: Provide ubiquitous access to learning support.

Participants liked the idea of ubiquitous learning, believing it would allow the whole world to become a learning resource. Participants expressed excitement about being able to fit learning around their daily activities. When considering the significance of ubiquitous learning in the learning model, it allows for contingent and situated learning, which are key elements in the preceding three pedagogical assumptions. Consequently, participants attached value to ubiquitous learning for the same reasons they attached value to the preceding three pedagogical assumptions; paying attention to and learning from visuals in one's environment was perceived as a good habit or best practice.

\section{Context-aware learning}

Pedagogical assumption 8: Provide context-aware learning.

Barnes (2011), Gombrich (1982), and Lester (2017) stated that context, that is the circumstances or environment for a visual message, needs to be considered when undertaking visual analysis. This presented a challenge for this learning model, because it is applied in a learner's unique and ever-changing environment. According to Basaeed, Berri, Zemerly, and Benlamri (2007), context-aware learning can dynamically change to reflect variations in the circumstances or conditions that surround a learner. The inclusion of this pedagogical assumption requires the use of a device, such as a smart phone, to poll contextual information such as location, time, and a visual's surroundings. This consequently situates this learning model as a specific implementation of m-learning due to its reliance on smart devices.

Participants were asked what contextual information they wanted to accompany the visuals. Roughly half the participants answered with a desire for the history or background information of the visuals, for example, who made it and why. However, one participant suggested that contextual information should be socially constructed. This socially constructed contextual information was imagined to be whatever the community wished to add about the visual, which in turn could be engaged with conversationally to clarify 
or modify meaning. Further, this participant perceived a system that provided set contextual information such as that voiced by the other participants (history, background, artists biographies), would be poor experience consisting of "being told" rather than actively participating in the learning. This split of participants' opinions has deeper pedagogical roots, mirroring the dichotomy observed between behaviourist and constructivist pedagogies. Due to the active role of the learner in constructivist pedagogies, the learner often has more control and learning can be more engaging (Leidner \& Jarvenpaa, 1995). As learner control and engagement are important considerations in informal learning, which lacks the external motivators of formal learning settings, constructivist learning assumptions may be more suitable for suitable for the style of learning proposed by this learning model. The participant's response may also explain why behaviourist or objectivist geo-located learning platforms such as Google Field Trip or Empedia never gained much traction.

The most discussed context feature throughout the test sessions was that of location. This was an expected result, given millennials' exposure to social media, in which geo-tagging photos and posts on platforms such as Facebook and Instagram are common. Participants envisioned geo-tagged information as a means navigating their present physical environment and as a means to browse environments remotely. The ability to browse remotely was an appealing proposition to participants who liked the idea of checking out locations they did not inhabit. The curiosity to see remote locations could potentially be used as a motivational factor to engage learners with visuals.

\section{Personalised learning}

Pedagogical assumption 9: Learning needs the ability to be personalised to accommodate a learner's environment, goals, interests, and preferences.

Personalised learning provides motivation according to gamification theory (Zichermann \& Cunningham, 2011) and intrinsic motivation to learn (Fazey \& Fazey, 2001). Participants' responses were however inconclusive in confirming this. The participants liked that they had preference settings to control how they learned, however these preferences appeared to be expected features rather than motivators. This can be understood through hygiene motivational theory, which posits that there are factors responsible for job satisfaction and an independent and separate set of factors responsible for job dissatisfaction called hygiene factors. The notion of hygiene factors has been applied and proven in user interface design by Miraz, Excell, and Ali (2016), who showed that some features, if included, do not contribute to satisfaction, but when excluded or neglected lead to dissatisfaction. These findings may also indicate a wider implication that learners' expectations have shifted. Whereas in 2001, Fazey and Fazey claimed personalisation could increase learner motivation, millennials observed in this study have had longer exposure to social media where such features are commonplace. This may have normalised or created expectations for personalisation features.

The ninth pedagogical assumption's sub-point, personalising learning needs to also include means to limit learning, is a response to scholarship from Gikas and Grant (2013) and Motiwalla (2007), who believed mlearning's anytime and anywhere learning can potentially overwhelm learners and intrude on their personal space. Highlighting seemed particularly vulnerable to these problems, as it sought to implement learning that would provide learning opportunities as numerous and persistent as visuals are. This is not practical and could overload a learner. Motiwalla (2007) also warned that this may lead to habituation, that is, the idea that we tune out repetitive stimulus. Habituation would result in learning prompts being ignored, or simply make learners disengage altogether. The inclusion of a supplementary assumption to limit learning was justified when one participant commented that if notifications ever became intrusive, they would disable them. This would be a poor outcome, as learners would not receive any prompts about visuals in their environment and disengage from learning. Further, participants desired different levels of notification. While one participant wanted up to 20 daily notifications, another felt that receiving more than 1 a week may be problematic. These findings confirm the caution Gikas and Grant (2013) and Motiwalla (2007) reported and demonstrated the need for learners to have controls to limit learning to cater to their individual needs. 


\section{Conclusion}

This research has sought to explore how the visuals one encounters every day can be leveraged as opportunities for learning visual literacy. This research revealed that there is potential for visuals in one's environment to be used as visual literacy learning opportunities provided there is learning support available. Consequently, this research pooled existing scholarship, tested and refined it, and synthesised a learning model.

The study has several implications. The learning style proposed by this study provides a means of visual literacy learning that has not been available to novice visual literacy learners. The style of learning described in the model places little, if any, burden or onus on educators or their institutes, therefore side-stepping traditional blockages in formal learning settings. This study has tested m-learning and related concepts, reconfirming ideas of collaborative learning, contingent learning, situated learning, authentic learning, context-aware learning, ubiquitous learning, and informal learning. It has further demonstrated how these concepts may operate in an informal and rhizomatic learning environment aimed at visual literacy acquisition. The research has potential for commercial outcomes, with an app already in development based on the learning model. The findings of this study have also demonstrated how visuals and geo-located visuals may be used as a means of engagement in m-learning. The learning model may also be of use in formal learning settings, more so if the pedagogical assumptions that form it are considered in isolation. The application of heuristic inquiry and user-centred design is uncommon in m-learning studies and may be useful as an example of ameliorating industry practise with academic research.

This study has two notable limitations. First, the participants were all located within Auckland, New Zealand and all had just completed a course called Visual Communication at Auckland University of Technology. The study may therefore have limited ecological validity. Second, this research has attempted to form a learning model that accommodates a variety of understandings of visual literacy rather than enter a debate on which disciplines or theories are correct. However, there is a bias towards a Helmholtzian or constructivist view of visual perception. This bias is a result of recognising the role of memory in perception, which allowed for connections to be drawn between perception and constructivist learning theory. While this helped bridge the field of visual literacy to learning, it may preclude other understandings of visual perception.

These outcomes of this study must be understood for what they are: first steps towards understanding and implementing visual literacy learning from one environment in a manner previously beyond that of novice learners. Consequently, informal visual literacy skills acquisition is an area fruitful for future research. The learning model needs further testing on a fully realised rhizomatic visual literacy learning community and has potential for improvement as the efficiency (how quickly knowledge is learned) and effectiveness (how long knowledge is retained) of such learning is unknown. As noted earlier, the learning model's pedagogical assumptions may function in isolation within formal learning settings, but this needs further research. Further, the premise of some of the assumptions, such as the effects of upwards and downwards comparison on visual learning gains have yet to be tested. Lastly, further testing could explore if the model has applications outside visual literacy acquisition.

\section{References}

Arnheim, R. (1969). Visual thinking. Berkeley, CA: University of California Press.

Asch, S. (1955). Opinions and Social Pressure. Scientific American, 193(5), 31-35. Retrieved from https://www.jstor.org/stable/24943779

Avgerinou, M., \& Ericson, J. (1997). A review of the concept of visual literacy. British Journal of Educational Technology, 28(4), 280-291. https://doi.org/10.1111/1467-8535.00035

Barnes, S. B. (2011). An introduction to visual communication: From cave art to second life (1st ed.). New York, NY: Peter Lang.

Basaeed, E., Berri, J., Zemerly, M., \& Benlamri, R. (2007). Web-based context-aware m-learning architecture. International Journal Interactive Mobile Technologies, 1(1), 5-10. Retrieved from https://online-journals.org/index.php/i-jim/article/view/167

Bleed, R. (2005). Visual literacy in higher education. Educause Learning Initiative. Retrieved from https://wcpss.pbworks.com/f/Visual+Literacy+in+HE.pdf 
Brill, J. M., Kim, D. \& Branch, R. M. (2007). Visual literacy defined - The results of a Delphi study: Can IVLA (operationally) define visual literacy? Journal of Visual Literacy, 27(1), 47-60. https://doi.org/10.1080/23796529.2007.11674645

Bruner, J. S. (1961). The act of discovery. Harvard Educational Review, 31, 21-32. Retrieved from https://psycnet.apa.org/record/1962-00777-001

Bruner, J. S. (1986). Actual minds, possible worlds. Cambridge, MA: Harvard University Press.

Cheong, C., Bruno, V., \& Cheong, F. (2012). Designing a mobile-app-based collaborative learning system. Journal of Information Technology Education: Innovations in Practice, 11(1), 94-119. Retrieved from https://www.learntechlib.org/p/111726

Cormier, D, (2008) Rhizomatic Education: Community as Curriculum. Innovate: Journal of Online Education, 4(5), Article 2. Retrieved from https://nsuworks.nova.edu/innovate/vol4/iss5/2

Crescente, M. L., \& Lee, D. (2011). Critical issues of m-learning: Design models, adoption processes, and future trends. Journal of the Chinese Institute of Industrial Engineers, 28(2), 111-123. https://doi.org/10.1080/10170669.2010.548856

Domínguez, A., Saenz-de-Navarrete, J., De-Marcos, L., Fernández-Sanz, L., Pagés, C., \& MartínezHerráiz, J.-J. (2013). Gamifying learning experiences: Practical implications and outcomes. Computers \& Education, 63, 380-392. https://doi.org/10.1016/j.compedu.2012.12.020

Deleuze, G., \& Guattari, F. (1988). A thousand plateaus: Capitalism and schizophrenia. Minneapolis, $\mathrm{MN}$ : University of Minnesota Press.

Dondis, D. A. (1973). A primer of visual literacy. Cambridge, MA: MIT Press.

Fazey, D. M. A., \& Fazey, J. A. (2001). The potential for autonomy in learning: Perceptions of competence, motivation and locus of control in first-year undergraduate students. Studies in Higher Education, 26(3), 345-361. https://doi.org/10.1080/03075070120076309

Festinger, L. (1954). A theory of social comparison processes. Human Relations, 7(2), 117-140. https://doi.org/10.1177/001872675400700202

Hanifan, T. (2008). It's more than reading and writing: The nature and extent of adult's literacy issues. In J. Benseman, A. Sutton, \& D. Coben (Eds.), Facing the challenge: Foundation learning for adults in Aotearoa New Zealand (pp. 125-135). Auckland: Dunmore Publishing Limited.

Georgiev, T., Georgieva, E., \& Smrikarov, A. (2004). M-learning: A new stage of e-learning. Proceedings of the International Conference on Computer Systems and Technologies-CompSysTech, 4, 1-5. https://doi.org/10.1145/1050330.1050437

Gikas, J., \& Grant, M. M. (2013). Mobile computing devices in higher education: Student perspectives on learning with cellphones, smartphones \& social media. The Internet and Higher Education, 19, 18-26. https://doi.org/10.1016/j.iheduc.2013.06.002

Gombrich, E. H. (1982). The image and the eye: Further studies in the psychology of pictorial representation. Oxford: Phaidon.

Griffin, M. (2008). Visual communication. In W. Donsbach (Ed.), The international encyclopedia of communication. Blackwell Reference Online. https://doi.org/10.1002/9781405186407.wbiecv016

Helmholtz, H. von. (1925). Treatise on physiological optics (Vol. 3). Menasha, WI: The Optical Society of America.

Jamieson, G. H. (2007). Visual communication: More than meets the eye. Chicago, IL: Intellect Books.

Kallio, H., Pietilä, A., Johnson, M., \& Kangasniemi, M. (2016). Systematic methodological review: Developing a framework for a qualitative semi-structured interview guide. Journal of Advanced Nursing, 72(12), 2954-2965. https://doi.org/10.1111/jan.13031

Leidner, D. E., \& Jarvenpaa, S. L. (1995). The use of information technology to enhance management school education: A theoretical view. MIS Quarterly, 19(3), pp. 265-291. Retrieved from http://www.jstor.org/stable/249596

Lester, P. M. (2017). Visual communication: Images with messages (7th ed.). Boston, MA: Wadsworth.

Marcum, J. W. (2002). Rethinking information literacy. The Library Quarterly, 72(1), 1-26. https://doi.org/10.1086/603335

Martin, B., \& Hanington, B. M. (2012). Universal methods of design (1st ed.). Beverly, MA: Rockport.

McMaster, S. (2015). Visual literacy and art education: A review of the literature. https://doi.org/10.13140/RG.2.1.4331.2482

Miraz, M. H., Excell, P. S., \& Ali, M. (2016). User interface (UI) design issues for multilingual users: A case study. Universal Access in the Information Society, 15(3), 431-444. https://doi.org/10.1007/s10209-014-0397-5

Motiwalla, L. F. (2007). Mobile learning: A framework and evaluation. Computers \& Education, 49(3), 581-596. https://doi.org/10.1016/j.compedu.2005.10.011 
Moustakas, C. (1990). Heuristic research: Design, methodology, and applications. London: Sage.

Muchnik, L., Aral, S., \& Taylor, S. J. (2013). Social influence bias: A randomized experiment. Science, 341(6146), 647-651. https://doi.org/10.1126/science.1240466

Muntean, C. I. (2011). Raising engagement in e-learning through gamification. Proceedings of the 6th International Conference on Virtual Learning, Cluj-Napoca, Romania, 323-329.

Nielsen, J. (2012). How many test users in a usability study. Nielsen Norman Group. Retrieved from https://www.nngroup.com/articles/how-many-test-users/

Nielsen, J., \& Landauer, T. K. (1993). A mathematical model of the finding of usability problems. Proceedings of the INTERACT'93 and CHI'93 Conference on Human Factors in Computing Systems, Amsterdam, 206-213. https://doi.org/10.1145/169059.169166

Olmsted-Hawala, E., \& Bergstrom, J. R. (2012). Think-aloud protocols: Does age make a difference. Proceedings of Society for Technical Communication (STC) Summit, Chicago, IL. Retrieved from https://www.academia.edu/1241322/Think-Aloud_Protocols_Does_Age_Make_a Difference

Park, J.-H., \& Choi, H. J. (2009). Factors influencing adult learners' decision to drop out or persist in online learning. Educational Technology \& Society, 12(4), 207-217. Retrieved from http://www.jstor.org/stable/jeductechsoci.12.4.207

Rock, I. (1997). Indirect perception. Cambridge, MA: MIT Press.

Rourke, A., \& Rees, V. (2015). Developing expertise in the visual domain. In A. Rourke, \& V. Rees (Eds.), Moving from novice to expert on the road to expertise: Developing expertise in the visual domain (pp. 1-11). Champaign, IL: Common Ground.

Schön, D. A. (1983). The reflective practitioner: How professionals think in action. New York, NY: Basic Books.

Selwyn, N. (2011). Editorial: In praise of pessimism - the need for negativity in educational technology. British Journal of Educational Technology, 42(5), 713-718. https://doi.org/10.1111/j.1467$\underline{8535.2011 .01215 . x}$

Spalter, A. M., \& Van Dam, A. (2008). Digital visual literacy. Theory into Practice, 47(2), 93-101. https://doi.org/10.1080/00405840801992256

Stokes, S. (2002). Visual literacy in teaching and learning: A literature perspective. Electronic Journal for the Integration of Technology in Education, 1(1), 10-19. Retrieved from https://wcpss.pbworks.com/f/Visual+Literacy.pdf

Suls, J., Martin, R., \& Wheeler, L. (2002). Social comparison: Why, with whom, and with what effect? Current Directions in Psychological Science, 11(5), 159-163. https://doi.org/10.1111/14678721.00191

Tan, W., Liu, D., \& Bishu, R. (2009). Web evaluation: Heuristic evaluation vs. user testing. International Journal of Industrial Ergonomics, 39(4), 621-627. https://doi.org/10.1016/j.ergon.2008.02.012

Tertiary Education Commission (2008). Learning progressions: For adult literacy. Wellington: Learning Media. Retrieved from https://ako.ac.nz/knowledge-centre/learning-progressions-for-adult-literacy/

Traxler, J. (2011). Mobile learning: Starting in the right place, going in the right direction. International Journal of Mobile and Blended Learning, 3(1), 57-67. https://doi.org/10.4018/978-1-4666-2139$\underline{8 . \operatorname{ch} 001}$

U.S. Department of Health and Human Services (2006). The research-based web design \& usability guidelines, enlarged/expanded edition. Washington, WA: U.S. Government Printing Office.

Velders, T., Vries, S., \& Vaicaityte, L. (2007). Visual literacy and visual communication for global education: Innovations in teaching e-learning in art, design and communication. Retrieved from https://research.utwente.nl/en/publications/visual-literacy-and-visual-communication-for-globaleducation-inn

Vogt, W. P. (2014). Selecting the right analyses for your data: Quantitative, qualitative, and mixed methods. New York, NY: Guilford Press.

Vredenburg, K., Mao, J.-Y., Smith, P. W., \& Carey, T. (2002). A survey of user-centered design practice. Proceedings of the SIGCHI Conference on Human Factors in Computing Systems, New York, NY, pp. 471-478. https://doi.org/10.1145/503376.503460

Vygotsky, L. S. (1978). Mind in society. Cambridge, MA: Harvard University Press.

Wills, T. A. (1981). Downward comparison principles in social psychology. Psychological Bulletin, 90(2), 245-271. https://doi.org/10.1037/0033-2909.90.2.245

Zichermann, G., \& Cunningham, C. (2011). Gamification by design: Implementing game mechanics in web and mobile apps. Sebastopol, CA: O’Reilly Media. 
Corresponding author: Matthew Guinibert, matt.guinibert@aut.ac.nz

Copyright: Articles published in the Australasian Journal of Educational Technology (AJET) are available under Creative Commons Attribution Non-Commercial No Derivatives Licence (CC BY-NC-ND 4.0). Authors retain copyright in their work and grant AJET right of first publication under CC BY-NC-ND 4.0.

Please cite as: Guinibert, M. (2020). Learn from your environment: A visual literacy learning model. Australasian Journal of Educational Technology, 36(4), 173-188. https://doi.org/10.14742/ajet.5200 